\title{
Dental Caries and Enamel Defects in Very Low Birth Weight Adolescents
}

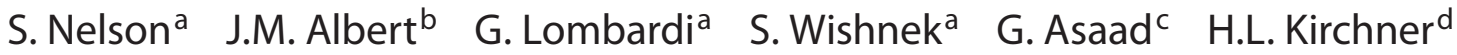 \\ L.T. Singer ${ }^{c}$ \\ ${ }^{a}$ Department of Community Dentistry, School of Dental Medicine, and Departments of ${ }^{b}$ Epidemiology and \\ Biostatistics and ' $\mathrm{G}$ General Medical Sciences and Pediatrics, School of Medicine, Case Western Reserve University, \\ Cleveland, Ohio, and ${ }^{\mathrm{d} C e n t e r}$ for Health Research, Geisinger Health System, Danville, Pa., USA
}

\section{Key Words}

Dental caries · Developmental enamel defects $\cdot$ Permanent teeth $\cdot$ Very low birth weight

\begin{abstract}
Objectives: The purpose of this study was to examine developmental enamel defects and dental caries in very low birth weight adolescents with high risk (HR-VLBW) and low risk (LR-VLBW) compared to full-term (term) adolescents. Methods: The sample consisted of 224 subjects ( $80 \mathrm{HR}-\mathrm{VLBW}, 59$ LR-VLBW, 85 term adolescents) recruited from an ongoing longitudinal study. Sociodemographic and medical information was available from birth. Dental examination of the adolescent at the 14-year visit included: enamel defects (opacity and hypoplasia); decayed, missing, filled teeth of incisors and molars (DMFT-IM) and of overall permanent teeth (DMFT); Simplified Oral Hygiene Index for debris/calculus on teeth, and sealant presence. A caregiver questionnaire completed simultaneously assessed dental behavior, access, insurance status and prevention factors. Hierarchical analysis utilized the zero-inflated negative binomial model and zeroinflated Poisson model. Results: The zero-inflated negative binomial model controlling for sociodemographic variables indicated that the LR-VLBW group had an estimated $75 \%$ increase $(p<0.05)$ in number of demarcated opacities in the incisors and first molar teeth compared to the term group.
\end{abstract}

Hierarchical modeling indicated that demarcated opacities were a significant predictor of DMFT-IM after control for relevant covariates. The term adolescents had significantly increased DMFT-IM and DMFT scores compared to the LRVLBW adolescents. Conclusion: LR-VLBW was a significant risk factor for increased enamel defects in the permanent incisors and first molars. Term children had increased caries compared to the LR-VLBW group. The effect of birth group and enamel defects on caries has to be investigated longitudinally from birth.

Copyright $\odot 2010$ S. Karger AG, Basel

The recent statistics indicate that the rate of very low birth weight (VLBW $<1,500 \mathrm{~g}$ ) continues to increase worldwide, and in the USA it is greater than 64,000 births annually [Hamilton et al., 2007]. It occurs most frequently with preterm birth and disproportionately among African-Americans and those of low socioeconomic status [Health Resources and Services Administration, 2002]. Medical and technological advances have reduced mortality for VLBW infants, but have resulted in an increased number of survivors who are at high risk for respiratory complications as a result of prematurity [Mercier and Soll, 1993; Martin and Walsh-Sukys, 1999]. Although VLBW infants represent a small percentage of the total births, they account for significantly increased health

\section{KARGER}

(C) 2010 S. Karger AG, Basel

Fax +4161306 1234

E-Mail karger@karger.ch

www.karger.com
Accessible online at: www.karger.com/cre
Suchitra Nelson

Department of Community Dentistry, School of Dental Medicine

Case Western Reserve University, 2123 Abington Road, Room DO3590

Cleveland, OH 44106-4905 (USA)

Tel. +1 216368 3469, Fax +1 216368 3204, E-Mail suchitra.nelson@ case.edu 
care costs [Agency for Healthcare Research and Quality, 2002], increased disabilities among the survivors [Wilson-Costello et al., 2005] and higher prevalence of functional limitations [Lewis et al., 2002; Short et al., 2003; Hack et al., 2005].

Similarly, a substantial burden of dental caries is found among minority, lower socioeconomic groups [BeltránAguilar et al., 2005] and those who are medically compromised or disabled [US Department of Health and Human Services, 2000]. VLBW children can be susceptible to dental caries due to biological and socioeconomic factors [Burt and Pai, 2001]. Biological problems include the increased prevalence of developmental defects of enamel (DDE: hypoplasia, demarcated and diffuse opacities) in the primary [Johnsen et al., 1984; Seow et al., 1987; Fearne et al., 1990; Kopra and Davis, 1991; Lai et al., 1997; Aine et al., 2000] and permanent dentition [Pimlott et al., 1985; Seow, 1996; Aine et al., 2000] as a result of systemic (illnesses/disturbances/deficiencies of prematurity) and local (trauma from endotracheal tubes) causes [Pindborg, 1982]. Developmental enamel defects are more prevalent in VLBW children who require prolonged oral endotracheal intubation [Moylan et al., 1980; Johnsen et al., 1984; Seow et al., 1984; Fearne et al., 1990; Kopra and Davis, 1991]. These defects typically persist at least 10 years into childhood [Kopra and Davis, 1991].

The common hypothesis for DDE in VLBW children during the neonatal period is through altered calcium homeostasis [Seow, 1997; Aine et al., 2000] because of the many systemic illnesses. Additionally, many high-risk VLBW (HR-VLBW) infants experience local factors because of orotracheal intubation and mechanical ventilation [Seow, 1997] that has a traumatic effect on the soft forming enamel resulting in enamel defects [Suckling, 1989; Seow, 1997]. DDE is thought to be the result of abrupt, short-term or long-term ameloblastic insults during the secretory or maturation phase of tooth development which can indicate if the insult occurred in utero or after birth [Suckling, 1989]. For the permanent incisors and first molars, the secretory phase begins in utero [Ten Cate, 1994] and the maturation phase starts at birth [Schour and Massler, 1941], and thus inadequate mineralization or trauma during these periods can result in DDE [Seow, 1996]. Demarcated opacities in early erupting permanent teeth (incisors and first molars) are associated with neonatal risk factors [Jalevik et al., 2001; Arrow, 2009] while diffuse opacities are associated with infant fluoride [Pendrys, 1999] and amoxicillin exposure [Hong et al., 2005]. Demarcated opacities in permanent teeth have been associated with caries in the precursor primary teeth [Lo et al., 2003; Broadbent et al., 2005; Arrow, 2009].

A few studies have suggested a relationship between preterm birth, birth weight and primary dental caries [Li et al., 1996; Lai et al., 1997; Saraiva et al., 2007a]. A significant association was found between caries and enamel hypoplasia in the primary dentition of VLBW children [Lai et al., 1997]. The two studies in the permanent dentition of low-birth-weight $(<2,500 \mathrm{~g})$ children have conflicting results regarding this association [Nicolau et al., 2003; Saraiva et al., 2007b]. These permanent dentition studies did not measure enamel defects as they relate to dental caries, nor did they look specifically at VLBW children.

Oral health behavior in relation to oral hygiene, dental access, insurance status, and exposure to fluorides and sealants has been poorly studied in VLBW children. The few studies have focused on the primary dentition of preterm and VLBW children controlling for some covariates [Lai et al., 1997; Saraiva et al., 2007a]. In this study, an a priori path model (fig. 1) was utilized for consideration of biological and environmental factors that lead to caries in the permanent dentition of adolescents.

We hypothesized that VLBW adolescents would have greater enamel hypoplasia and nonfluoride opacity (demarcated opacity), and consequently more dental caries because of postpartum medical problems (local and systemic insults to the developing permanent teeth) compared to term healthy children. The study focused on early erupting incisors and first molar permanent teeth which calcify within 4 months after birth [Schour and Massler, 1941] that would be most affected by medical problems. Thus, the primary objectives of this study were: (1) to examine the effect of birth group on developmental enamel defects (enamel hypoplasia and demarcated opacity) after controlling for relevant demographic factors; (2) to examine in a hierarchical manner utilizing the path model (fig. 1) the relative contribution of sets of covariates (including demographics, birth group, developmental enamel defects, dental access and prevention factors) on dental caries.

\section{Materials and Methods}

\section{Study Sample}

The sample was recruited from a cohort of children participating in a longitudinal study evaluating the effects of VLBW on neurodevelopment [Singer et al., 1997]. Subjects and their parents from the original cohort were recruited from 3 independent 
Cleveland hospital sites whose neonatal intensive-care units treated all infants with medical complications.

HR-VLBW children had all of the following characteristics: (1) diagnosis of bronchopulmonary dysplasia, a chronic pulmonary condition of prematurity [Mercier and Soll, 1993; Martin and Walsh-Sukys, 1999]; (2) preterm birth less than or equal to 36 weeks' gestational age; (3) birth weight less than 1,500 g; (4) required supplementary oxygen for greater than 28 days; (5) radiographic evidence of chronic lung disease.

Low-risk children with VLBW (LR-VLBW) did not have a diagnosis of bronchopulmonary dysplasia, were preterm, weighing less than $1,500 \mathrm{~g}$ at birth, and required oxygen supplementation for less than 25 days. Full-term subjects (term) were healthy, of greater than 36 weeks gestational age and weighed greater than $2,500 \mathrm{~g}$ at birth for singleton infants. During the recruitment period (1989-1991), for each HR-VLBW infant, the next-born LRVLBW infant and term infant of the same race and socioeconomic status were recruited. Infants with major neurological problems, congenital malformations, alcohol or drug exposure, mothers that had major psychiatric or physical illness, HIV exposure, mental retardation or who lived greater than $2 \mathrm{~h}$ driving distance away were excluded. Extensive neonatal medical information and demographic data were collected from the hospital charts or maternal interviews. The original cohort consisted of 321 subjects (115 HR-VLBW, 83 LR-VLBW and 123 term) who were followed from birth until 14 years of age. The participation rate at the 14 -year visit was $84 \%(268 / 321)$ for the original study.

A total of 246 subjects were seen in the dental study. The remaining 22 subjects of the original study were either seen prior to the start of the dental study or refused to participate in the dental study. With further exclusion of 22 subjects (due to incomplete records, severe medical problems, orthodontic braces), the final dental study sample consisted of 224 subjects. The study was approved by the Institutional Review Board of the participating hospital, and written informed consent and assent were obtained from the parent/caregiver and adolescent, respectively.

\section{Study Design}

A retrospective cohort design was used since the birth group was formed prior to the dental examinations at 14 years of age and existing prior demographic and medical assessments were utilized to study the dental outcomes of the children at adolescence.

\section{Procedures}

\section{Sociodemographic and Medical Assessments}

Sociodemographic and medical data were collected during enrollment in the original longitudinal study and have been described previously [Singer et al., 1997]. At birth, the data were taken from the hospital chart or maternal interview and included the following: infant birth weight (grams), infant gestational age (weeks), supplemental oxygen (days), ventilation (days), gender, ethnicity, maternal age, education and socioeconomic status using Hollingshead's [1965] classification (class I, II, III: middle to high class; class IV and V: lower class) of social class.

During the 14-year visit, maternal and adolescent interviews added the following variables: current marital status, number of

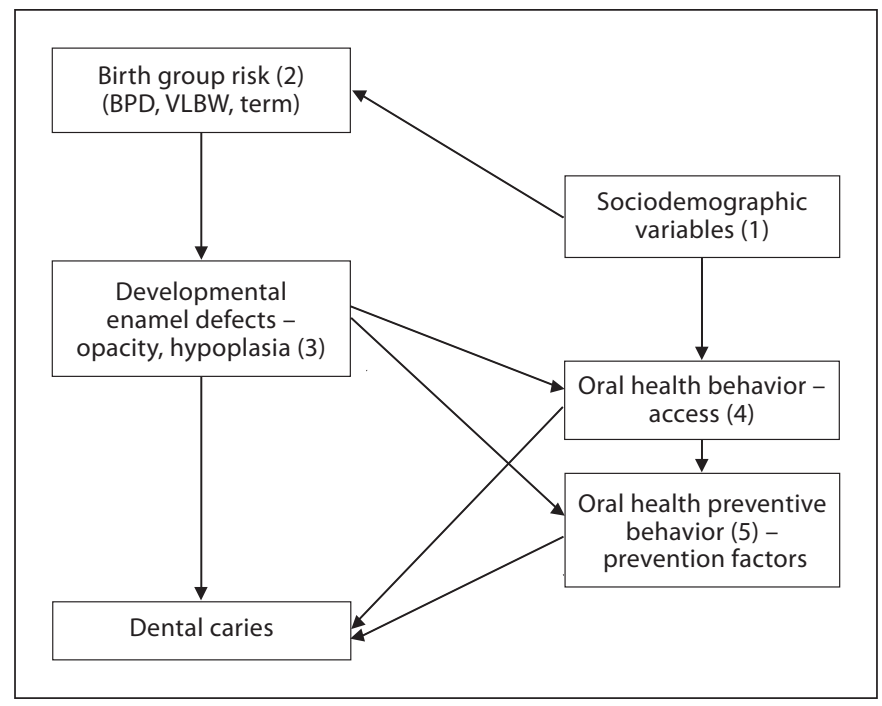

Fig. 1. Conceptual model of the time sequence between birth group and dental caries. The hierarchical model includes these sets of variables: (1) sociodemographics; (2) birth group; (3) enamel defects; (4) dental access behavior; (5) prevention factors. $\mathrm{BPD}=$ Bronchopulmonary dysplasia.

children at home, adolescent body mass index computed from height and weight, and whether the adolescent currently received physical, occupational, speech or psychological therapies.

\section{Oral Health Questionnaires}

Parent questionnaires adapted from a prior study [Oliveira et al., 2006] were used during the 14-year visit to determine adolescents' dental behavior, insurance status during the last month, frequency of dental visits, fluoride use and other oral health prevention exposures over their lifetime. The questionnaire responses were categorized or collapsed for purposes of analysis. Dental access variables included insurance type (categorized as none, Medicaid, other, both Medicaid and other) and frequency of dentist visits (categorized as an ordinal score: $0=$ none or rarely; $1=$ less than 2 years; 2 = every 2 years; 3 = every year). Preventive dental factors from the questionnaire inquired if the adolescent had ever received fluoride treatments (i.e. fluoride varnish, fluoride supplements, fluoridated mouth rinses) and the number of months of brushing supervision given by the parent/caregiver during the adolescent's lifetime.

\section{Dental Examinations}

Dental examinations were conducted by 1 trained and calibrated examiner (G.L.) masked to the adolescents' birth group status. Intraoral photographs, frontal and lateral views, were obtained from all subjects except those with mental or physical disabilities who could not tolerate the procedure or follow instructions. For the purpose of interexaminer and intraexaminer reliabilities, random photographs were examined by a second experienced examiner.

The Simplified Oral Hygiene Index for debris was obtained from all subjects as an objective measure of brushing behavior in 
the adolescent [Green and Vermillion, 1964]. The score ranges from 0 to 6, with higher scores indicating greater debris covering the teeth. The dental examiner also recorded the presence of sealants on the permanent molars.

The presence of dental caries was determined according to the criteria of Radike [1968] and included the number of decayed, missing, filled teeth of incisors and first molars (DMFT-IM), and DMFT of all teeth. The permanent incisors and first molars were of particular interest due to the time line of calcification of these teeth after birth [Schour and Massler, 1941] and the likelihood of these teeth being affected by poor mineralization/trauma due to complications of prematurity [Seow, 1996]. Further, perinatal VLBW data from 14 centers of the National Institute of Child Health and Human Development Neonatal Research Network indicated that the mean length of hospital stay (as a surrogate for medical problems) was between 40 and 116 days depending on the birth weight [Lemons et al., 2001]. Hence, permanent incisors and first molars were analyzed separately.

The DDE Index [Commission on Oral Health, Research and Epidemiology, 1982] was utilized to determine the presence and classification of enamel defects. Tooth surfaces were examined wet, and heavy plaque deposits were removed for DDE examination. To test the hypothesis of this study, the analysis focused on developmental defects (hypoplasia, demarcated opacity) in the incisor and first molar permanent teeth. These included the number of demarcated opacities (white or discolored change in enamel translucency with a clearly defined boundary and not diffuse) in the incisors and first molar teeth (opacity-IM) and the number of single/multiple hypoplastic (break in enamel continuity with pits or grooves) lesions on incisors and first molar teeth (hypoplasia-IM).

\section{Statistical Analysis}

The comparison of sociodemographic and medical variables, dental access, and preventive dental factors among the 3 birth groups were analyzed using the $\mathrm{F}$ test for continuous data and the $\chi^{2}$ test for categorical data. The unadjusted comparison of caries (DMFT and DMFT-IM) and enamel defects (opacity-IM and hypoplasia-IM) between the 3 groups were analyzed using the F test.

The zero-inflated negative binomial method was used to model the distribution of responses for DMFT, opacity-IM and hypoplasia-IM while the zero-inflated Poisson method was used to model DMFT-IM which tended to have lower expected counts and less overdispersion [Cheung, 2002; Lewsey and Thomson, 2004]. In addition, the mean for each variable was modeled via nonlinear regression as a function of covariates. A hierarchical modeling approach was used, whereby sets of covariates were added cumulatively in the order indicated by an a priori path model (fig. 1). Thus, the hierarchical models for enamel defect outcomes involved only the demographic (race, sex, socioeconomic status and age) and birth group variables ( 2 indicator variables for the 3 groups: HRVLBW, LR-VLBW and term). For the dental caries outcomes, the following 5 sets (in the listed order) were used in the hierarchical models: (1) demographic variables; (2) birth group; (3) enamel defects (opacity-IM and hypoplasia-IM for DMFT-IM, and demarcated opacities and hypoplasia in all teeth for DMFT); (4) access variables (insurance type and frequency of dental visits); (5) preventive dental factors (any fluoride treatment, brushing supervision, sealant presence and Simplified Oral Hygiene Index).
The focus was on 2 comparisons among the 3 groups (term vs. LR-VLBW and term vs. HR-VLBW). These comparisons were considered as distinct and separately interpretable, and thus were not adjusted for multiplicity. Maximum likelihood was used to obtain estimates of the percent increase in the mean for a 1-unit increase (or the specified category versus the reference category) for each covariate. Approximate $\Delta$ method t tests and $\mathrm{F}$ tests were used to test for an effect on the mean response of each covariate and each set of covariates, respectively. In the hierarchical approach, the estimates and tests of interest for each set of covariates are those obtained when they are 'just added' to the model. $\mathrm{R}^{2}$ statistics were calculated using the likelihood ratio statistic for the contribution of each added set [Lipsitz et al., 2001]. The zero-inflated negative binomial and zero-inflated Poisson models were fit using SAS 9.1 Proc NLMIXED (SAS Institute). Statistical significance was based on a 0.05 alpha level criterion.

The kappa statistic was calculated for opacity, hypoplasia and caries to determine percent agreement between the examiner (G.L.) and an independent experienced examiner. The kappa values indicated good to excellent (0.51-0.83) interexaminer and intraexaminer reliability.

\section{Results}

The sample consisted of 224 subjects ( 80 HR-VLBW, 59 LR-VLBW, 85 healthy term adolescents). The mean age at examination was $15.0 \pm 0.77$ years with $47 \%$ male, $48 \%$ African-American and $61 \%$ low socioeconomic status. Maternal characteristics at birth and at the 14-year visit were similar between the 3 groups (table 1). At birth, the VLBW adolescents were significantly of lower birth weight, lower gestational age, and were on supplemental oxygen and ventilation (table 1). At the 14-year visit, a significantly greater proportion of VLBW adolescents were receiving occupational therapy.

In the dental access variables (table 2), insurance status was significantly $(\mathrm{p}<0.05)$ different between the 3 groups with a higher proportion of HR-VLBW adolescents without dental insurance and Medicaid participation highest in the LR-VLBW group. Among the prevention factors (table 2), the VLBW groups had significantly $(\mathrm{p}<0.05)$ greater mean months of supervised brushing from parent/caregiver compared to the term group. The overall unadjusted means (table 2) indicate that the 3 groups were not different in the caries or enamel defect assessments. However, pairwise comparisons indicated that the number of demarcated opacities in the LR-VLBW were significantly $(\mathrm{p}<0.05)$ higher compared to the term group.

The hierarchical model estimates (table 3 ) of percent mean increases (or decreases) found a significant effect of the demographic variables on mean opacity-IM ( $\mathrm{p}=$
Nelson/Albert/Lombardi/Wishnek/ Asaad/Kirchner/Singer 
Table 1. Maternal and child characteristics at birth and at the 14-year follow-up (means, SD in parentheses)

\begin{tabular}{|c|c|c|c|c|}
\hline Characteristic & $\begin{array}{l}\text { HR-VLBW } \\
(\mathrm{n}=80)\end{array}$ & $\begin{array}{l}\text { LR-VLBW } \\
(\mathrm{n}=59)\end{array}$ & $\begin{array}{l}\text { Term } \\
(\mathrm{n}=85)\end{array}$ & $\mathrm{p}$ value \\
\hline \multicolumn{5}{|l|}{ At birth-maternal } \\
\hline Age, years & $28.3(5.5)$ & $28.3(6.1)$ & $27.85(6.3)$ & 0.89 \\
\hline Education, years & $13.3(2.2)$ & $13.3(2.2)$ & $13.5(2.5)$ & 0.81 \\
\hline Low SES, \% & 55 & 66 & 62 & 0.39 \\
\hline \multicolumn{5}{|l|}{ At birth - child } \\
\hline Birth weight, $g$ & $977.1(248.3)$ & $1,272.9(185.1)$ & $3,415.7(528.8)$ & 0.00 \\
\hline Gestational age, weeks & $27.5(2.1)$ & $30.5(2.3)$ & $39.7(1.3)$ & 0.00 \\
\hline Oxygen duration, days & $108.5(164.7)$ & $4.7(4.2)$ & $0.0(0.0)$ & 0.00 \\
\hline Ventilation duration, days & $35.6(27.1)$ & $2.8(3.0)$ & $0.0(0.0)$ & 0.00 \\
\hline Male, $\%$ & 55 & 36 & 47 & 0.09 \\
\hline African-American, \% & 44 & 49 & 52 & 0.67 \\
\hline \multicolumn{5}{|c|}{ At 14-year follow-up - maternal } \\
\hline Marital status, \% single & 65 & 59 & 57 & 0.60 \\
\hline Children, $\mathrm{n}$ & $2.4(1.1)$ & $2.7(1.2)$ & $2.6(1.5)$ & 0.21 \\
\hline \multicolumn{5}{|l|}{ At 14-year follow-up - child } \\
\hline Mean age, years & $15.2(0.9)$ & $15.0(0.7)$ & $14.9(0.6)$ & 0.10 \\
\hline BMI & $24.5(6.5)$ & $23.6(5.8)$ & $25.4(7.1)$ & 0.26 \\
\hline Physical therapy, \% & 13 & 9 & 4 & 0.10 \\
\hline Occupational therapy, $\%$ & 11 & 5 & 1 & 0.02 \\
\hline Speech therapy, \% & 18 & 12 & 6 & 0.07 \\
\hline Psychotherapy, \% & 8 & 5 & 13 & 0.21 \\
\hline
\end{tabular}

$\mathrm{SES}=$ Socioeconomic status; BMI = body mass index. Italics indicate values significant at $\mathrm{p}<0.05$.

0.02). Ethnicity and age were the significant predictors of opacity-IM. In the birth group variables, the LRVLBW had a $75 \%$ increase in mean number of demarcated opacities that was significant $(\mathrm{p}=0.03)$ compared to the term group. The overall $\mathrm{R}^{2}$ was $8 \%$, with the estimated effect of all covariates (demographic variables and birth group) on opacity-IM being significant ( $\mathrm{p}=0.01)$. No significant effect of the covariates on hypoplasia-IM was found.

The hierarchical model (table 4) found an overall significant effect of demographic variables on DMFT-IM and DMFT ( $\mathrm{p}=0.001)$. Being female and low socioeconomic status were significantly associated with increased mean DMFT-IM and DMFT. For birth group, an overall significant effect was found only for DMFT ( $p=0.04)$. The term group had an estimated $71.6 \%$ significant increase in mean DMFT counts compared to the LRVLBW group. An overall significant effect of enamel defects was found only for DMFT-IM ( $p=0.01)$. Among the enamel defect variables, a unit increase in opacity-IM had an estimated $18.2 \%$ significant increase in mean DMFT-IM. We did not find an overall significant effect of the set of access or prevention variables for either DMFT-IM or DMFT. Among the access variables, frequency of dental visits and sealant presence were significant predictors of DMFT-IM, and 2 additional variables (insurance status and Simplified Oral Hygiene Index) were significant predictors of the overall DMFT score. Approximately $27 \%\left(\mathrm{R}^{2}=0.27, \mathrm{p}<0.001\right)$ of the variation in both DMFT-IM and DMFT were explained by the 5 sets of variables.

\section{Discussion}

\section{Enamel Defects in VLBW}

To our knowledge this is the first study of the extent of dental caries and enamel defects in the permanent teeth of HR- and LR-VLBW adolescents compared with term adolescents. Our findings indicate that demarcated enamel opacity in the permanent incisors and molars was significantly higher for the LR-VLBW compared to term adolescents, and suggest that permanent teeth that calcify soon after birth are vulnerable to systemic in- 
Table 2. Unadjusted comparison of dental access, preventive behavior and dental outcomes between the 3 groups at the 14-year follow-up

\begin{tabular}{|c|c|c|c|c|}
\hline Variable & $\begin{array}{l}\text { HR-VLBW } \\
(\mathrm{n}=80)\end{array}$ & $\begin{array}{l}\text { LR-VLBW } \\
(\mathrm{n}=59)\end{array}$ & $\begin{array}{l}\text { Term } \\
(\mathrm{n}=85)\end{array}$ & $\mathrm{p}$ value \\
\hline \multicolumn{5}{|l|}{ Dental access } \\
\hline \multicolumn{5}{|l|}{ Insurance status, \% } \\
\hline None & 22 & 10 & 6 & \multirow[t]{4}{*}{0.04} \\
\hline Medicaid & 9 & 21 & 14 & \\
\hline Other & 48 & 53 & 60 & \\
\hline Both Medicaid and other & 21 & 16 & 20 & \\
\hline \multicolumn{5}{|l|}{ Dental visit frequency, \% } \\
\hline None or rarely & 4 & 2 & 1 & \multirow[t]{4}{*}{0.80} \\
\hline$<2$ years & 6 & 12 & 10 & \\
\hline Every 2 years & 8 & 7 & 5 & \\
\hline Every year & 82 & 79 & 84 & \\
\hline \multicolumn{5}{|l|}{ Prevention factors } \\
\hline Fluoride treatments, \% yes & 66 & 70 & 62 & 0.64 \\
\hline Sealants, \% yes & 29 & 25 & 28 & 0.89 \\
\hline Simplified Oral Hygiene Index scores & $1.3 \pm 0.9$ & $1.1 \pm 0.6$ & $1.2 \pm 0.8$ & 0.34 \\
\hline Brushing supervision, months & $102.5 \pm 48.2$ & $99.8 \pm 43.2$ & $79.8 \pm 36.4$ & 0.00 \\
\hline \multicolumn{5}{|l|}{ Dental outcomes } \\
\hline DMFT-IM scores & $1.06 \pm 1.6$ & $1.00 \pm 1.5$ & $1.49 \pm 1.7$ & 0.13 \\
\hline Total DMFT scores & $1.70 \pm 3.1$ & $1.56 \pm 2.1$ & $2.39 \pm 2.9$ & 0.15 \\
\hline DMFT-IM, \% yes & 42 & 42 & 53 & 0.28 \\
\hline DMFT, $\%$ yes & 43 & 54 & 59 & 0.12 \\
\hline Opacity-IM, n & $0.81 \pm 1.5$ & $1.24 \pm 1.9$ & $0.73 \pm 1.2$ & $0.12^{1}$ \\
\hline Hypoplasia-IM, n & $0.34 \pm 0.90$ & $0.41 \pm 1.0$ & $0.33 \pm 0.76$ & 0.86 \\
\hline
\end{tabular}

Results are means \pm SD or percentages as indicated. Italics indicate values significant at $\mathrm{p}<0.05$.

${ }^{1}$ Significant difference between VLBW and term groups at $\mathrm{p}<0.05$.

Table 3. Hierarchical estimates of percent increase in mean demarcated opacity and hypoplasia in incisors and first molar teeth

\begin{tabular}{|c|c|c|c|c|c|c|}
\hline \multirow{2}{*}{$\begin{array}{l}\text { Covariate } \\
\text { (category vs. reference } \\
\text { group or unit change) }\end{array}$} & \multicolumn{3}{|c|}{ Opacity-IM } & \multicolumn{3}{|c|}{ Hypoplasia-IM } \\
\hline & $\%$ increase & SE & $\mathrm{p}$ value & $\%$ increase & SE & $\mathrm{p}$ value \\
\hline Race (black vs. white) & 73.1 & 45.0 & 0.04 & -6.9 & 35.6 & 0.85 \\
\hline Sex (female vs. male) & 12.4 & 25.2 & 0.60 & 9.6 & 37.8 & 0.79 \\
\hline SES (low vs. high) & -2.3 & 26.5 & 0.93 & 10.4 & 42.2 & 0.80 \\
\hline Age $(+1$ year $)$ & -31.1 & 11.1 & 0.02 & 21.3 & 25.8 & 0.36 \\
\hline Sociodemographics & \multicolumn{3}{|c|}{$\mathrm{R}^{2}=0.057 \quad \mathrm{p}=0.02$} & \multicolumn{3}{|c|}{$\mathrm{R}^{2}=0.013 \quad \mathrm{p}=0.90$} \\
\hline Birth group (HR-VLBW vs. term) & 30.7 & 35.3 & 0.32 & -7.4 & 37.9 & 0.85 \\
\hline Birth group (LR-VLBW vs. term) & 74.5 & 44.4 & 0.03 & 20.9 & 50.6 & 0.65 \\
\hline Birth group & \multicolumn{2}{|c|}{$\mathrm{R}^{2}=0.028$} & .09 & \multicolumn{2}{|c|}{$\mathrm{R}^{2}=0.003$} & $p=0.83$ \\
\hline Overall & \multicolumn{2}{|c|}{$\mathrm{R}^{2}=0.083$} & 0.01 & \multicolumn{2}{|c|}{$\mathrm{R}^{2}=0.016$} & .95 \\
\hline
\end{tabular}

$\mathrm{SE}=$ Standard error; $\mathrm{SES}=$ socioeconomic status. Italics indicate values significant at $\mathrm{p}<0.05$. 
Table 4. Hierarchical estimates of percent increase in mean decayed, missing, filled teeth of all (DMFT) and only in incisors and first molar teeth (DMFT-IM)

\begin{tabular}{|c|c|c|c|c|c|c|}
\hline \multirow{2}{*}{$\begin{array}{l}\text { Covariate } \\
\text { (category vs. reference } \\
\text { group or unit change) }\end{array}$} & \multicolumn{3}{|l|}{ DMFT-IM } & \multicolumn{3}{|l|}{ DMFT } \\
\hline & $\%$ increase & SE & $\mathrm{p}$ value & $\%$ increase & $\mathrm{SE}$ & $\mathrm{p}$ value \\
\hline Race (black vs. white) & 20.9 & 23.0 & 0.32 & -0.35 & 19.8 & 0.99 \\
\hline Sex (female vs. male) & 48.0 & 26.0 & 0.03 & 43.7 & 26.4 & 0.05 \\
\hline SES (low vs. high) & 81.5 & 40.7 & 0.01 & 103.6 & 46.0 & 0.00 \\
\hline Age $(+1$ year $)$ & 10.5 & 12.9 & 0.39 & 18.0 & 14.3 & 0.17 \\
\hline Sociodemographics & \multicolumn{2}{|c|}{$\mathrm{R}^{2}=0.11$} & $\mathrm{p}=0.00$ & \multicolumn{2}{|c|}{$\mathrm{R}^{2}=0.12$} & $\mathrm{p}=0.00$ \\
\hline Birth group (term vs. HR-VLBW) & 26.1 & 26.2 & 0.27 & 33.5 & 29.6 & 0.20 \\
\hline Birth group (term vs. LR-VLBW) & 60.1 & 35.4 & 0.04 & 71.6 & 36.8 & 0.01 \\
\hline Birth group & \multicolumn{2}{|c|}{$\mathrm{R}^{2}=0.028$} & $\mathrm{p}=0.10$ & \multicolumn{2}{|c|}{$\mathrm{R}^{2}=0.050$} & $\mathrm{p}=0.04$ \\
\hline Opacity demarcated (+1 tooth) & 18.2 & 6.8 & 0.00 & 3.5 & 2.4 & 0.14 \\
\hline Hypoplasia (+1 tooth) & 6.9 & 10.5 & 0.50 & 7.7 & 5.4 & 0.14 \\
\hline Enamel defects & \multicolumn{2}{|c|}{$\mathrm{R}^{2}=0.053$} & $\mathrm{p}=0.01$ & \multicolumn{2}{|c|}{$\mathrm{R}^{2}=0.033$} & $\mathrm{p}=0.13$ \\
\hline Insurance (Medicaid vs. none) & 65.9 & 74.0 & 0.26 & 68.0 & 71.7 & 0.23 \\
\hline Insurance (other insurance vs. none) & 61.4 & 62.6 & 0.22 & 123.1 & 87.3 & 0.04 \\
\hline Insurance (both insurance vs. none) & -16.0 & 36.0 & 0.68 & 36.6 & 58.8 & 0.47 \\
\hline Visit $(+1$ category $)$ & -23.4 & 10.2 & 0.05 & -32.8 & 10.2 & 0.01 \\
\hline Access & \multicolumn{2}{|c|}{$\mathrm{R}^{2}=0.053$} & $\mathrm{p}=0.15$ & \multicolumn{2}{|c|}{$\mathrm{R}^{2}=0.045$} & $\mathrm{p}=0.06$ \\
\hline Fluoride (any treatment vs. none) & 47.7 & 30.8 & 0.06 & 35.1 & 30.2 & 0.18 \\
\hline Sealant ( 0 vs. $\geq 1)$ & 58.7 & 36.6 & 0.049 & 64.6 & 41.3 & 0.049 \\
\hline Months supervised (+1 month) & 1.0 & 0.24 & 0.95 & $<0.10$ & 0.26 & 0.77 \\
\hline OHI-S (+1 unit) & 3.2 & 2.4 & 0.18 & 5.1 & 2.5 & 0.03 \\
\hline Prevention factors & \multicolumn{2}{|c|}{$\mathrm{R}^{2}=0.056$} & $\mathrm{p}=0.08$ & \multicolumn{2}{|c|}{$\mathrm{R}^{2}=0.051$} & $\mathrm{p}=0.08$ \\
\hline Overall & \multicolumn{2}{|c|}{$\mathrm{R}^{2}=0.27$} & $\mathrm{p}<0.001$ & \multicolumn{2}{|c|}{$\mathrm{R}^{2}=0.27$} & $\mathrm{p}<0.001$ \\
\hline
\end{tabular}

$\mathrm{SE}=$ Standard error; SES = socioeconomic status; OHI-S = Simplified Oral Hygiene Index. Italics indicate values significant at $\mathrm{p}<0.05$.

sults. Demarcated opacities in the developing permanent teeth can be a result of long-lasting/sudden insults to the enamel-forming cells, ameloblasts during the secretory phase (in utero) or severe disturbances during the maturation phase in the first year of life [Suckling, 1989; Jalevik et al., 2001]. Prior studies [Jalevik et al., 2001; Arrow, 2009] have reported that health problems such as infections and respiratory diseases during the first few months after birth were important risk factors for demarcated opacities in the early erupting permanent teeth. In this study, the increased oxygen use and ventilation following birth in the LR-VLBW compared to term adolescents is evidence of the health problems that could have had an effect on the maturation phase of enamel formation.

While the HR-VLBW adolescents also had higher demarcated opacities, they were not significantly different from the term adolescents. The HR-VLBW adolescents had a significantly greater number of days on ventilation at birth, but this did not translate to more enamel problems in the permanent dentition. Due to the longer hospitalization for the HR-VLBW group [Klinger et al., 2006]; we speculate that this could also translate to closer monitoring of these children. At 14 years, the VLBW children had significantly more functional limitations as noted from the increased physical, occupational and speech therapies needed than the term adolescents. This finding, however, also indicates that they receive more coordinated care and are linked to various health care systems, perhaps resulting in greater awareness and access to dental providers, a factor that might reduce the burden of dental problems. Although a higher proportion of the HR-VLBW group had no dental insurance during the past month at the 14-year assessment, it could be that 
they may have had prior insurance coverage that was not captured by our questionnaire. In fact, US national survey results [Liu et al., 2007] indicate that children with special health needs had a higher likelihood of having dental insurance and using more preventive services than children without special needs.

Enamel hypoplasia was however not related to VLBW status in the adolescents, a finding contrary to prior investigations [Seow, 1996; Aine et al., 2000] of permanent teeth in preterm children. Enamel hypoplasia was not as prevalent (19\%) compared to opacities (40\%) in our sample, a finding [Seow, 1996] similar to a previous study. Enamel hypoplasia was not predictive of caries either, perhaps due to the small number of adolescents with these defects.

It is also possible that the pattern of enamel defects that we found in our sample could be indicative of the molar-incisor hypomineralization [Willmott et al., 2008]. Since the focus of our study was not on investigating the molar-incisor hypomineralization spectrum, we did not specifically use the criteria of Weerheijm et al. [2003] for diagnosing molar-incisor hypomineralization. Moreover, in our sample all other teeth besides first permanent molars and incisors were also affected by demarcated opacities. Since all other permanent teeth calcify after early infancy, we could not be certain that enamel defects in these teeth were due to complications of prematurity and thus focused on the first molars and incisors.

\section{Dental Caries in VLBW Children}

We did not find increased caries in the VLBW groups. We explain these results as follows. First, since our adolescents were part of an ongoing cohort study, the VLBW children could have received timely care. In fact, a recent study [Gravina et al., 2006] indicated that caries in the primary teeth was lower among premature compared to term children, due to the preterm ones being followed routinely with appropriate oral health care, while term children were referred to physicians for regular pediatric care. However, Saraiva et al. [2007a] using the US National Health and Nutrition Examination Survey III data set reported that preterm birth was associated with increased dental caries in the primary teeth, but not in children with intrauterine growth retardation (IUGR). The determinants of low birth weight are preterm birth and/or IUGR [Kramer, 1987]. In this study, all our VLBW adolescents were born before term, and it could be plausible that some had IUGR. Some of the reasons speculated by Saraiva et al. [2007a] for a negative association of caries with IUGR such as de- layed tooth eruption and accelerated enamel maturation could not be explored with our data. However, antibiotic use may have been higher in our sample, due to the many health problems of prematurity and VLBW. The frequent use of antibiotics has been indicated as inhibiting the colonization of cariogenic bacteria [Fukuda et al., 2005] that may possibly explain the reduced caries experience in our VLBW adolescents. Specific antibiotic use information was not available for this study and hence remains a speculation. Second, the behavioral data from our study indicate that caregivers were providing brushing assistance/supervision for the VLBW groups for a significantly longer period than for the term group. Supervised tooth brushing has been reported to be an effective preventive strategy for caries prevention in young children [Tinanoff et al., 2002]. Also, dental sealant presence in our sample (28\%) was lower than the national rate of $37 \%$ [Beltrán-Aguilar et al., 2005], indicating that at least in the term group a combination of risk factors could have resulted in higher caries. Third, sociodemographic variables were the most significant predictor of approximately $11-12 \%$ of the variation in DMFT-IM and DMFT scores, consistent with prevalence findings from national surveys [Beltrán-Aguilar et al., 2005]. This indicates that environmental factors have a huge influence on caries in the permanent dentition, exceeding earlier biological influences.

The study also found that demarcated opacities were a significant predictor of caries in the incisors and molars of permanent teeth which is similar to prior findings [Ellwood and O'Mullane, 1994, 1996] in 12- to 14-yearold schoolchildren. Demarcated opacities in the permanent teeth have also been reported to be twice more likely if caries had been present in the primary precursor [Lo et al., 2003; Broadbent et al., 2005; Arrow, 2009]. Thus, it is probable that the LR-VLBW adolescents with demarcated opacities could have had a carious primary precursor tooth that was not possible to assess in this study.

Limitations of the study include: (1) Potential recall information bias for the parental questionnaire since the parent/caregiver was aware of the birth group status of the adolescent - but it is unlikely that the dental access, prevention and behavior questions could have been skewed based on the parent/caregiver knowing the birth group status of the adolescent. (2) There could have been some misclassification bias due to the failure to distinguish between posteruptive enamel loss in hypomineralized areas and caries in permanent molars and incisors; 
such a bias could have influenced the association between demarcated opacities and caries, but this bias should be minimal due to the use of 1 study examiner, training and calibration on the dental assessments, and the excellent reliability of the examiner for caries diagnosis. (3) The absence of dental data prior to the 14-year visit renders us unable to compare the sequelae of dental problems in the VLBW groups.

In conclusion, our data suggest that developmental enamel defects persist in the permanent incisors and molars of LR-VLBW adolescents. Since oral health is essential for systemic health [US Department of Health and Human Services, 2000], more longitudinal studies from birth of medically compromised children such as VLBW infants are needed to investigate the various mediating and confounding factors on caries.

\section{Acknowledgements}

We acknowledge Ms. Sarah Fulton, Ms. Nicole Herbst and Mr. Paul Weishampl in the collection of the data. This investigation was supported in part by Research Grants R21-DE16469 (to S.N.) and R03 DE018391 (to J.M.A.) from the National Institute of Dental and Craniofacial Research, National Institutes of Health, Bethesda, Md., USA, and Research Grants MC-390592, MC00127 and MC-00334 (to L.T.S.) from the Maternal and Child Health Program, Health Resources and Services Administration, Department of Health and Human Services, Rockville, Md., USA.

\section{Disclosure Statement}

The authors have no financial relationship relevant to this article to disclose.

\section{References}

Agency for Healthcare Research and Quality: Criteria for determining disability in infants and children: low birth weight. US Department of Health and Human Services Publ 70, 2002.

- Aine L, Backström MC, Mäki R, Kuusela AL, Koivisto AM, Ikonen RS, Mäki M: Enamel defects in primary and permanent teeth of children born prematurely. J Oral Pathol Med 2000;29:403-409.

Arrow P: Risk factors in the occurrence of enamel defects of the first permanent molars among schoolchildren in Western Australia. Community Dent Oral Epidemiol 2009;37: 405-415.

-Beltrán-Aguilar ED, Barker LK, Canto MT, Dye BA, Gooch BF, Griffin SO, Hyman J, Jaramillo F, Kingman A, Nowjack-Raymer R, Selwitz RH, Wu T: Centers for Disease Control and Prevention (CDC): surveillance for dental caries, dental sealants, tooth retention, edentulism, and enamel fluorosis United States, 1988-1994 and 1999-2002. MMWR Surveill Summ 2005;54:1-43.

Broadbent JM, Thomson WM, Williams SM: Does caries in primary teeth predict enamel defects in permanent teeth? A longitudinal study. J Dent Res 2005;84:260-264.

Burt BA, Pai S: Does low birth weight increase the risk of caries? A systematic review. J Dental Educ 2001;65:1024-1027.

Cheung YB: Zero-inflated models for regression analysis of count data: a study of growth and development. Stat Med 2002;21:1461-1469.

Commission on Oral Health, Research and Epidemiology: An epidemiological index of developmental defects of dental enamel (DDE Index). Int Dent J 1982;32:159-167.
-Ellwood RP, O'Mullane D: The association between developmental enamel defects and caries in populations with and without fluoride in their drinking water. J Public Health Dent 1996;56:76-80.

Ellwood RP, O'Mullane DM: Association between dental enamel opacities and dental caries in a north Wales population. Caries Res 1994;28:383-387.

- Fearne JM, Bryan EM, Elliman AM, Brook AH Williams DM: Enamel defects in the primary dentition of children born weighing less than 2,000 g. Br Dent J 1990;168:433-437.

Fukuda JT, Sonis AL, Kurth S: Acquisition of mutans streptococci and caries prevalence in pediatric sickle cell anemia patients receiving long term antibiotic therapy. Pediatr Dent 2005;27:186-190.

-Gravina DBL, Cruvinel VRN, Azevedo TDPL, Toledo OAD, Bezerra ACB: Prevalence of dental caries in children born prematurely or at full term. Braz Oral Res 2006;20:353-357.

Green JC, Vermillion JR: The simplified oral hygiene index. J Am Dent Assoc 1964;68:25-31.

Hack M, Taylor HG, Drotar D, Schulchter M, Cartar L, Andreias L, Wilson-Costello D, Klein N: Chronic conditions, functional limitations and special health care needs of school-aged children born with extremely low-birth-weight in the 1990s. JAMA 2005; 294:318-325.

Hamilton BE, Martin JA, Sutton PD, Ventura SJ: Births: preliminary data for 2007. National Vital Statistics Report 2009;57:1-23.

Health Resources and Services Administration: US Department of Health and Human Services: child health USA, very low birth weight. 2002. http://mchb.hrsa.gov/chusa02.

Hollingshead AB: Two Factor Index of Social Position. New Haven, Yale Station, 1965.
-Jalevik B, Noren JG, Klingberg G, Barregard L: Etiologic factors influencing the prevalence of demarcated opacities in permanent first molars in a group of Swedish children. Eur J Oral Sci 2001;109:230-234.

Johnsen D, Krejci C, Hack M, Fanaroff A: Distribution of enamel defects and the association with respiratory distress in very low birthweight infants. J Dent Res 1984;63:59-64.

Klinger G, Sirota L, Lusky A, Reichman B: Bronchopulmonary dysplasia in very low birth weight infants is associated with prolonged hospital stay. J Perinatol 2006;26:640-644.

Kopra DE, Davis EL: Prevalence of oral defects among neonatally intubated 3 - to 5 - and 7- to 10-year old children. Pediatr Dent 1991;13: 349-355.

Kramer MS: Determinants of low birth weight: methodological assessment and meta-analysis. Bull World Health Organ 1987;65:663737.

Lai PY, Seow WK, Tudehope DI, Rogers Y: Enamel hypoplasia and dental caries in very-low birthweight children: a case-controlled, longitudinal study. Pediatr Dent 1997;19:42-49.

Lemons JA, Bauer CR, Oh W, Korones S, Papile LA, Stoll BJ, Verter J, Temprosa M, Wright LL, Ehrenkranz R, Fanaroff AA, Stark AR, Carlo WA, Tyson JE, Donovan E, Shankaran $\mathrm{S}$, Stevenson DK: Very low birth weight outcomes of the National Institute of Child Health and Human Development Neonatal Research Network, January 1995 through December 1996. Pediatrics 2001;107:E1.

Lewis BA, Singer LT, Fulton S, Salvator A, Short EJ, Klein N, Baley J: Eight year speech and language outcomes of children with a history of bronchopulmonary dysplasia and very low birth weight. J Commun Disord 2002;35: 393-406. 
Lewsey JD, Thomson WM: The utility of the zero-inflated Poisson and zero-inflated negative binomial models: a case study of cross-sectional and longitudinal DMF data examining the effect of socio-economic status. Community Dent Oral Epidemiol 2004; 32:183-189.

Li Y, Navia JM, Bian JY: Caries experience in deciduous dentition of rural Chinese children 3-5 years old in relation to the presence or absence of enamel hypoplasia. Caries Res 1996;30:8-15

- Lipsitz SR, Leong T, Ibrahim J, Lipshultz S: A partial correlation coefficient and coefficient of determination for multivariate normal repeated measures data. J R Stat Soc Ser D 2001;50:87-95.

- Liu J, Probst JC, Martin AB, Wang JY, Salinas CF: Disparities in dental insurance coverage and dental care among US children: the National Survey of Children's Health. Pediatrics 2007;119:S12-S20.

Lo EC, Zheng CG, King NM: Relationship between the presence of demarcated opacities and hypoplasia in permanent teeth and caries in their primary predecessors. Caries Res 2003;37:456-461.

-Martin RJ, Walsh-Sukys MC: Bronchopulmonary dysplasia - no simple solution. N Engl J Med 1999;340:1036-1038.

Mercier C, Soll R: Clinical trials of natural surfactant in respiratory distress syndrome. Clin Perinatol 1993;20:723-725.

-Moylan FM, Seldin EB, Shannon DC, Todres ID: Defective primary dentition in survivors of neonatal mechanical ventilation. J Pediatr 1980;96:106-108.

-Nicolau B, Marcenes W, Bartley M, Sheiham A: A life course approach to assessing causes of dental caries experience: the relationship between biological, behavioral, socio-economic and psychological conditions and caries in adolescents. Caries Res 2003;37:319-326.
Oliveira AFB, Chaves AMB, Rosenblatt A: The influence of enamel defects on the development of early childhood caries in a population with low socioeconomic status: a longitudinal study. Caries Res 2006;40:296-302.

-Pendrys DG: Analytical studies of enamel fluorosis: methodological considerations. Epidemiol Rev 1999;21:233-246.

Pimlott JFL, Howley TP, Nikiforuk G, Fitzhardinge PM: Enamel defects in prematurely born, low birthweight infants. Pediatr Dent 1985; 7:218-223.

Pindborg JJ: Aetiology of developmental enamel defects not related to fluorosis. Int Dent J 1982;32:123-134.

Radike AW: Criteria for Diagnosis of Dental Caries. Proceedings of the Clinical Testing of Cariostatic Agents, Oct 14-16, 1968, Chicago. Chicago, American Dental Association 1968.

Saraiva MCD, Bettiol H, Barbieri MA, Silva AA: Are intrauterine growth restriction and preterm birth associated with dental caries? Community Dent Oral Epidemiol 2007a;35: 364-376.

Saraiva MCD, Chiga S, Bettiol H, Silva AA, Barbieri MA: Is low birthweight associated with dental caries in permanent dentition? Pediatr Perinatal Epidemiol 2007b;21:49-56.

Schour I, Massler M: The development of the human dentition. J Am Dent Assoc 1941;28: 1153-1160.

Seow WK: A study of the development of the permanent dentition in very low birthweight children. Pediatr Dent 1996;18:379-384.

- Seow WK: Effects of preterm birth on oral growth and development. Aust Dent J 1997; 42:85-91.

Seow WK, Brown JP, Tudehope DI, O'Callaghan M: Developmental defects in the primary dentition of low birth-weight infants: adverse effects of laryngoscopy and prolonged endotracheal intubation. Pediatr Dent 1984; 6:28-31.

-Seow WK, Humphrys C, Tudehope DI: Increased prevalence of developmental dental defects in low-birth-weight children: a controlled study. Pediatr Dent 1987;9:221-225.
$>$ Short EJ, Klein NK, Lewis BA, Fulton S, Eisengart S, Kercsmar C, Baley J, Singer LT: Cognitive and academic consequences of bronchopulmonary dysplasia and very low birth weight: eight-year-old outcomes. Pediatrics 2003;112:359-366.

-Singer LT, Yamashita TS, Lilien L, Collin M, Baley J: A longitudinal study of infants with bronchopulmonary dysplasia and very low birthweight. Pediatrics 1997;100:987-993.

Suckling GW: Developmental defects of enamel - historical and present-day perspectives of their pathogenesis. Adv Dent Res 1989;3: 87-94.

Ten Cate AR: Development of the tooth and its supporting tissues; in Ten Cate AR (ed): Oral Histology, ed 4. St Louis, Mosby, 1994, pp 45-80.

Tinanoff N, Kanellis MJ, Vargas CM: Current understanding of the epidemiology mechanisms, and prevention of dental caries in preschool children. Pediatr Dent 2002;24:543546.

US Department of Health and Human Services: Oral health in America: a report of the surgeon general. USDHHS, National Institute of Dental and Craniofacial Research, National Institutes of Health, 2000

Weerheijm KL, Duggai M, Mejare I, et al: Judgement criteria for molar-incisor-hypomineralisation (MIH) in epidemiologic studies: a summary of the European meeting on MIH held in Athens 2003. Eur Arch Paediatr Dent 2003;3:110-113.

Willmott NS, Bryan RAE, Duggai MS: Molarincisor-hypomineralisation. a literature review. Eur Arch Paediatr Dent 2008;9:172179.

Wilson-Costello D, Friedman H, Minich N, Faranoff AA, Hack M: Improved survival rates with increased neurodevelopmental disability for extremely low birthweight infants in the 1990s. Pediatrics 2005;115:997-1003. 